\title{
Habilidades Sociais no Brasil
}

\author{
Bandeira, M., Del Prette, Z. A. P., \& Del Prette, A. (2006). (Orgs.). Estudos sobre Habilidades \\ Sociais e Relacionamento Interpessoal. São Paulo,SP: Casa do Psicólogo.
}

A obra em questão é uma publicação conjunta de pesquisadores que desenvolvem estudos na área das habilidades sociais em crianças e adultos. Contempla o relato de investigações científicas, análise de instrumentos e procedimentos de avaliação e revisão teórica sob o foco das relações interpessoais.

No primeiro capítulo, Área das habilidades sociais no Brasil: uma análise de estudos publicados em periódicos, os autores Alessandra Turini Bolsoni-Silva, Zilda A. P. Del Prette, Giovana Del Prette, Ana Roberta P. Montanher, Mariana Bandeira e Almir Del Prette identificam e analisam a produção acadêmica nacional disponível em periódicos de Psicologia, de forma a caracterizar a área, possibilitando identificar tendências e possíveis lacunas de pesquisas a fim de facilitar novos encaminhamentos investigações na área. Esse texto possibilita ao leitor uma visão atualizada das temáticas mais abordadas na área bem como ratifica sua consolidação como campo de pesquisa e aplicação.

O capítulo dois Avaliação muldimodal de habilidades sociais em crianças: Procedimentos, instrumentos e indicadores, escrito por Zilda A. P. Del Prette e Almir Del Prette, descreve alguns dos procedimentos e instrumentos comumente utilizados para avaliar habilidades sociais numa abordagem multimodal. Há apresentação dos aspectos conceituais da abordagem adequados às características desenvolvimentais e sócio-demográficas de acordo com as necessidades e objetivos da avaliação. Desta maneira, este texto especifica os diferentes critérios da avaliação do repertório de habilidades sociais de crianças.

No terceiro capítulo, Crianças com bom desempenho acadêmico: Dificuldades comportamentais e eventos de vida, os autores Sonia Regina Loureiro e Simone H. Bianchi Sanches expõem aspectos relacionados ao bom desempenho acadêmico, sob a perspectiva desenvolvimentalista, como uma forma de favorecer o desenvolvimento de crianças que apresentam dificuldades comportamentais, destacando-se a maneira como elas percebem os eventos de vida. $O$ texto foi dividido em três partes, sendo que a primeira se refere à associação entre o desempenho acadêmico e adaptação social; a segunda aborda os efeitos vitais como acontecimentos do cotidiano, que exigem adaptação; e a terceira e última parte, relata dados de um estudo empírico com crianças que apresentam um bom desempenho acadêmico, porém com dificuldades comportamentais e de sociabilidade, no qual associa-se o perfil comportamental às percepções sobre os eventos de vida.

A qualidade da interação pais e filhos e sua relação com problemas de comportamentos de pré-escolares, é o título do quarto capítulo de Alessandra Turini BolsoniSilva e Edna Maria Marturano. Fazem um relato de pesquisa descrevendo as relações entre pais e filhos, comparando a habilidade social educativa parental, entre diferentes grupos, no âmbito familiar, social e escolar. Constatou-se, dentre outros resultados, que as mães das crianças socialmente competentes, apresentam melhor repertório de habilidades sociais educativas, em relação às mães de crianças com indicação escolar de problemas de comportamentos.

A amizade aparece como tema no capítulo cinco, Aspectos psicológicos da amizade na infãncia, no qual Agnaldo Garcia apresenta uma revisão da literatura internacional sobre os aspectos psicológicos da amizade na infância. São abordadas algumas considerações sobre a amizade e a família, a origem da amizade e como esta influencia as relações existentes no interior da família. $O$ texto discute sobre as redes de amigos, o melhor amigo e as fases da amizade, bem como, o processo de escolha, estabilidade, e mudanças na amizade, considerando crianças com necessidades especiais. Alguns processos psicossociais são relatados nas relações de amizade, 
como similaridade e intimidade; cooperação prósocial e competição; popularidade, rejeição, negligência, abuso, depressão e solidão, dentre outros.

No capítulo seis, Qualidade de interação familiar: Instrumento de medida e programas de prevenção, Lidia Natalia Dobrianskyj Weber, Ana Paula Viezzer Salvador e Olívia Justen Brandenburg descrevem um relato de um estudo realizado com a Escala de Qualidade de Interação Familiar (EQIF), que avalia a partir de práticas parentais e aspectos da interação familiar, se as crianças ou adolescentes encontram-se em situação de risco, normal ou proteção. A pesquisa foi realizada por meio de um programa grupal de orientação e treinamento de pais, em encontros semanais que possibilitavam vivências e discussões sobre educação entre pais e filhos, com o objetivo de desenvolver habilidades, facilitando assim, a aplicação de métodos eficazes de educação. Os resultados mostram que os filhos de famílias com maior qualidade de interação apresentam maior auto-estima e melhor desempenho em habilidades sociais, menor nível de estresse e menor índice de depressão.

Baseando-se em reflexões feitas sobre autores que abordam a questão, o texto do capítulo sete, Treinamento de habilidades sociais na escola: $O$ método vivencial e a participação do professor, escrito por Zilda A. P. Del Prette e Almir Del Prette, remete ao treinamento de habilidades sociais. Este texto descreve as atividades realizadas na preparação, aplicação e avaliação, por um grupo de professoras que utilizaram o método de vivências, em um programa de treinamento realizado com crianças em uma escola municipal. Inicialmente, o capítulo aborda algumas considerações sobre a educação escolar, dificuldade de ensino e de aprendizagem. E, após é apresentado o relato de experiência em problemas comportamentais internalizantes e esternalizantes, descrevendo-se os aspectos teóricos e metodológicos. Também foi relatado à metodologia de um programa de promoção do desenvolvimento socioemocional, descrevendo a participação das professoras, a avaliação, até a discussão das implicações práticas e de pesquisas.

O Comportamento assertivo: relações com ansiedade lócus de controle e auto-estima, compõem o título do capítulo oito, no qual Marina Bandeira e Maria Amélia Cesari Quaglia descrevem o comportamento assertivo, como uma subclasse das habilidades sociais. O texto é dividido, basicamente, em duas partes; a primeira refere-se aos modelos explicativos dos déficits de assertividade, destacando as repercussões no bem estar psicológico; e, uma revisão de pesquisas sobre comportamento assertivo relacionando-se com ansiedade, lócus de controle e auto-estima. A segunda parte apresenta a descrição de um estudo realizado com estudantes universitários brasileiros, de forma a identificar se o comportamento assertivo está relacionado com menor grau de ansiedade, maior grau de internalidade e maior auto-estima.

Com base nas reflexões feitas As habilidades sociais na adaptação de estudantes ao ensino superior, de autoria de Eliane Gerk e Miguez Cunha, intitula o capítulo nove, trazendo a perspectiva do ensino superior como um período crítico, de grandes desafios. É discutido que a superação dessa etapa depende do desenvolvimento psicossocial do aluno, bem como da instituição de ensino e dos mecanismos de apoio oferecidos por ela. Com base neste ponto de vista, e considerando as demandas de conhecimentos e competências exigidas dos universitários, foi realizado um estudo correlacional entre as habilidades sociais, inteligência e vivências acadêmicas. Foram aplicados, um Questionário de Vivências Acadêmicas, uma Bateria de Provas de Raciocínio e um Inventário de Habilidades Sociais, que possibilitaram a discussão de programas facilitadores do desenvolvimento psicossocial e do sucesso acadêmico do estudante.

No décimo capítulo, Desenvolvimenro de habilidades sociais em graduandos de Psicologia, os autores Patrícia Pacheco e Bernard Rangé descrevem a realização de um Treinamento de Habilidades Sociais no Curso de Psicologia. Primeiramente foi identificada a necessidade do desenvolvimento de um repertório de habilidades sociais, enquanto recurso necessário para uma prática profissional competente. Assim, os autores descrevem um estudo com o objetivo de verificar se um programa sintético poderia ser uma estratégia eficaz. Os resultados sugeriram que o programa mostrou-se eficaz para a maior parte das 
habilidades treinadas exigindo, porém o rendimento e o aprimoramento de alguns programas específicos nos quais não se observou uma mudança significativa.

No ultimo capítulo, Treinamento de habilidades sociais em grupos com estudantes de Psicologia: Avaliando um programa de intervenção os autores Almir Del Prette, Zilda A. P. Del Prette e Maria Cecília M. Barreto descrevem um programa de Desenvolvimento Interpessoal Profissional (PRODIP), como um delineamento quase-experimental, um grupo de treinamento e outro de controle, com medidas repetidas de pré e pós-intervenção. $A$ intervenção foi realizada em grupo e organizada em dois módulos (teórico/informativo e prático-vivencial), os procedimentos utilizados foram, ensaio comportamental, feedack, reestruturação cognitiva e resolução de problemas. Também foram descritos os resultados, que indicaram diferenças significativas entre os grupos, favoráveis ao de intervenção.

As referências dos assuntos apresentados no livro encontram-se ao final de cada capítulo, possibilitando ao leitor uma consulta posterior. A leitura deste livro é recomendada a todos os profissionais da área da saúde e em particular da área da educação, uma vez que oferece vários temas atuais que possibilitam a reflexão e a compreensão do assunto abordado. Ao lado disso, disponibiliza instrumental de apoio às atividades cotidianas realizadas pelos profissionais e incita os pesquisadores à investigação científica.

Anelise Silva Dias Psicóloga 